\title{
The effects of green tea on weight loss and weight maintenance: a meta-analysis.
}

Citation for published version (APA):

Hursel, R., Viechtbauer, W., \& Westerterp-Plantenga, M. S. (2009). The effects of green tea on weight loss and weight maintenance: a meta-analysis. International Journal of Obesity, 33(9), 956-961.

https://doi.org/10.1038/ijo.2009.135

Document status and date:

Published: 01/01/2009

DOI:

10.1038/ijo.2009.135

Document Version:

Publisher's PDF, also known as Version of record

\section{Document license:}

Taverne

\section{Please check the document version of this publication:}

- A submitted manuscript is the version of the article upon submission and before peer-review. There can be important differences between the submitted version and the official published version of record.

People interested in the research are advised to contact the author for the final version of the publication, or visit the DOI to the publisher's website.

- The final author version and the galley proof are versions of the publication after peer review.

- The final published version features the final layout of the paper including the volume, issue and page numbers.

Link to publication

\footnotetext{
General rights rights.

- You may freely distribute the URL identifying the publication in the public portal. please follow below link for the End User Agreement:

www.umlib.nl/taverne-license

Take down policy

If you believe that this document breaches copyright please contact us at:

repository@maastrichtuniversity.nl

providing details and we will investigate your claim.
}

Copyright and moral rights for the publications made accessible in the public portal are retained by the authors and/or other copyright owners and it is a condition of accessing publications that users recognise and abide by the legal requirements associated with these

- Users may download and print one copy of any publication from the public portal for the purpose of private study or research.

- You may not further distribute the material or use it for any profit-making activity or commercial gain

If the publication is distributed under the terms of Article $25 \mathrm{fa}$ of the Dutch Copyright Act, indicated by the "Taverne" license above, 


\title{
The effects of green tea on weight loss and weight maintenance: a meta-analysis
}

\author{
R Hursel $^{1}$, W Viechtbauer ${ }^{2}$ and MS Westerterp-Plantenga ${ }^{1}$ \\ ${ }^{1}$ Department of Human Biology, Nutrition and Toxicology Research Institute Maastricht (NUTRIM) Maastricht University, \\ Maastricht, The Netherlands and ${ }^{2}$ Department of Methodology and Statistics, Maastricht University, Maastricht, \\ The Netherlands
}

Introduction. Different outcomes of the effect of green tea on weight loss (WL) and weight maintenance (WM) have been reported in studies with subjects differing in ethnicity and habitual caffeine intake.

Purpose. To elucidate by meta-analysis whether green tea indeed has a function in body weight regulation.

Methods. English-language studies about WL and WM after green tea supplementation were identified through PubMed and based on the references from retrieved articles. Out of the 49 studies initially identified, a total of 11 articles fitted the inclusion criteria and provided useful information for the meta-analysis. Effect sizes (mean weight change in treatment versus control group) were computed and aggregated based on a random-effects model. The influence of several moderators on the effect sizes was examined.

Results. Catechins significantly decreased body weight and significantly maintained body weight after a period of WL $(\hat{\mu}=-1.31 \mathrm{~kg} ; P<0.001)$. Inhibition of this effect by high habitual caffeine intake ( $>300 \mathrm{mg}$ per day) failed to reach significance $(\hat{\mu}=-0.27 \mathrm{~kg}$ for high and $\hat{\mu}=-1.60 \mathrm{~kg}$ for low habitual caffeine intake; $P=0.09)$. Also, the seemingly smaller effect of catechins in Caucasian $(\hat{\mu}=-0.82 \mathrm{~kg})$ subjects compared with Asians $(\hat{\mu}=-1.51 \mathrm{~kg} ; P=0.37)$ did not reach significance. Interaction of ethnicity and caffeine intake was a significant moderator $(P=0.04)$.

Conclusions. Catechins or an epigallocatechin gallate (EGCG)-caffeine mixture have a small positive effect on WL and WM. The results suggest that habitual caffeine intake and ethnicity may be moderators, as they may influence the effect of catechins. International Journal of Obesity (2009) 33, 956-961; doi:10.1038/ijo.2009.135; published online 14 July 2009

Keywords: green tea; caffeine; weight loss; weight maintenance; ethnicity

\section{Introduction}

Green tea is the most widely consumed beverage next to water in Asian countries. Moreover, people in Asia have been aware of the beneficial effects of green tea on health for already hundreds of years. ${ }^{1}$ On the other hand, only recently is green tea gaining interest in the Westernized world, where mainly black tea is drunken. Green tea is made from the fresh leaves of Camellia sinensis, which are processed rapidly by means of steam to prevent fermentation. Black tea is made from the same plant as green tea but the leaves endure an extra enzymatic oxidation step during the processing. ${ }^{1}$ The polyphenols in green tea such as epigallocatechin gallate (EGCG), epigallocatechin, and epicatechin gallate, which are

Correspondence: R Hursel, Department of Human Biology, Maastricht University, Universiteitssingel 50, P.O. Box 616, Maastricht, 6200 MD, The Netherlands.

E-mail: rick.hursel@hb.unimaas.nl

Received 30 January 2009; revised 18 May 2009; accepted 2 June 2009; published online 14 July 2009 responsible for its beneficial effects (such as the anti-oxidant potential and anti-mutagenic capacity) are converted into thearubigins and theaflavins in black tea. ${ }^{2}$ Although black tea still can improve one's health, the conversion attenuates the effects reported after intake of green tea. ${ }^{3-5}$

Since the 1990s, green tea is also seen as a natural herb that can enhance energy expenditure and fat oxidation and thereby induce weight loss (WL). ${ }^{6,7}$ The fact that an EGCG-caffeine mixture stimulates energy expenditure cannot be completely attributed to its caffeine content because the thermogenic effect of an EGCG-caffeine mixture is greater than that of an equivalent amount of caffeine. ${ }^{8}$ Twenty-four hour studies showed a significant increase in energy expenditure and fat oxidation. ${ }^{8,9}$ From these shortterm studies, studies over the longer term originated in which the effect from an EGCG-caffeine mixture on WL was studied and soon studies concerning the effect on weight maintenance (WM) followed.

Almost all of the studies conducted with Asian subjects have shown positive results about the anti-obesity effects of 
catechins. ${ }^{10-17}$ On the other hand, studies with Caucasian subjects reported mixed results. ${ }^{18-20}$ Moreover, the amount of regular caffeine intake may also influence the effectiveness of catechins. In a study from WesterterpPlantenga et al., ${ }^{20}$ it was shown that a regular caffeine intake of $>300 \mathrm{mg}$ per day in Caucasian subjects diminished the effects of an EGCG-caffeine mixture on WM, in comparison with subjects that had a regular caffeine intake of $<300 \mathrm{mg}$ per day.

Hence, the aim of this study was to do a systematic review and meta-analysis of all the available long-term studies that have examined the effects of EGCG on WL and WM, to establish whether catechins contribute to the regulation of body weight. Possible moderators, such as regular caffeine intake and ethnicity, are included in the meta-analysis, to investigate whether they have any impact on the effects of an EGCG-caffeine mixture on body weight.

\section{Methods}

\section{Identification of relevant studies}

PubMed was searched for English-language studies that reported the long-term effects from catechins on WL and WM. The databases were searched up to July 2008 with the following keywords: green tea, body weight, WL, WM, catechins, epigallocatechin gallate or EGCG. References from the retrieved articles were examined to identify possible additional articles.

\section{Inclusion and exclusion criteria}

A study was valid for inclusion in the review if (a) the study's participants were randomly assigned to conditions, (b) the results allowed a direct comparison of the effects of catechins (either in the form of catechins versus no catechins or high dosage versus low dosage catechins) on either WL or WM, (c) subjects were kept blind to the condition assigned, and (d) the study lasted for at least 12 weeks. An EGCG-caffeine mixture tea could either be administered as regular tea or as capsules. An important exclusion criterion was the use of any tea other than an EGCG-caffeine mixture (such as oolong tea).

\section{Data abstraction}

Various characteristics were extracted from the original reports using a standardized data extraction form. We recorded the study's author(s), year of publication, the duration of the treatment phase (in weeks), whether the study used a WL or WM design, and the age range, ethnicity, average body mass index, gender, and average regular caffeine intake (in mg per day) of the participants in the study. Moreover, for each condition, we recorded the number of participants and the dosage of green tea administered (in mg per day).
For each condition, we calculated or extracted the mean weight change (in kilograms) between the post-treatment and the baseline assessment. For WL studies, the baseline corresponds to the point just before the commencement of the WL phase, whereas for WM studies, the baseline corresponds to the point before the commencement of the WM phase. The post-treatment mean was always based on the time point immediately following the intervention. Regardless of the study design, negative values for the mean change, therefore, indicate $\mathrm{WL}$, a value of zero indicates no change, and positive values indicate an increase in the body mass on average. The effect size measure for the metaanalysis was then the difference between the mean change value for the treatment minus the mean change value for the control group. Negative values for the observed effect size, therefore, indicate more WL (or less weight gain) on average in the treatment compared with the control group and, therefore, a positive treatment effect of the EGCG-caffeine mixture on WL/WM.

The following three variables were a priori chosen for examination as potential moderators: the ethnicity of the participants (either Asian or Caucasian), the average regular caffeine intake of the participants in the study (either low or high, with $300 \mathrm{mg}$ per day being the cutoff), and the difference in dosage of the EGCG-caffeine mixture administered in the treatment and the control group.

\section{Statistical analysis}

The effect size estimates were aggregated based on a randomeffects model, using restricted maximum-likelihood (REML) estimation to estimate the amount of heterogeneity in the effect sizes. ${ }^{21}$ We report the estimated average effect $(\hat{\mu})$, the estimated amount of heterogeneity in the true effects $\left(\hat{\tau}^{2}\right)$, and the estimated percentage of the total amount of variability that can be attributed to heterogeneity $\left(I^{2}\right)$. Corresponding 95\% confidence intervals are given for all of these statistics. We also provide the results from the test for heterogeneity. The moderators were examined individually and in combination using mixed-effects models, again using REML estimation for the amount of (residual) heterogeneity. For these models, we report the estimated effect sizes within each level of a moderator with corresponding $95 \%$ confidence intervals.

\section{Results}

Forty-four potentially relevant studies were found initially. From these, 15 review articles were excluded immediately, as these contributed no additional data besides the original studies, which were already included. Another 13 studies were excluded on the basis of title and abstract, as these were studies conducted with animals. Five articles from Asian authors were obtained through personal communication. ${ }^{10-12,14,17}$ Four of them only had an English abstract 
and were further written in Japanese. These articles were sent to us with an English translation, as we contacted the institution (Kao Corporation, Tokyo, Japan) where Nagao et al $^{13}$ are employed, after finding their study in PubMed. Information from the fifth Asian study by Wang et al. ${ }^{17}$ was also obtained through personal communication, as the results were not published during the data abstraction. Of the remaining 21 studies, 9 did not use green tea (e.g., oolong tea) or did not provide sufficient information to compute effect sizes. Only one study was excluded because of the time period, as it lasted for 8 weeks. No studies were excluded because of lack of randomization or blinding. Finally, 11 articles fulfilled the inclusion criteria. ${ }^{10-20}$ Figure 1 shows the process of study selection.

The selected articles all had comparable designs: in the WL studies, ${ }^{10-18}$ participants immediately started to consume an EGCG-caffeine mixture for 12 weeks following randomization; in the WM studies, ${ }^{19,20}$ subjects first lost weight for 4 weeks using a very low energy diet, followed by randomization and then an EGCG-caffeine mixture supplementation for either 12 or 13 weeks (Table 1 ). In all but one study, ${ }^{17}$ subjects were randomly assigned to two conditions, with seven studies ${ }^{10,15-20}$ using a true placebo group and the remaining four studies ${ }^{11-14}$ comparing a high with a low dose of an EGCG-caffeine mixture.

Almost every article reported the relevant information about the moderators, for instance as an important inclusion criterion. If regular caffeine intake was not reported by the Asian studies, it was assumed to be low. ${ }^{22}$

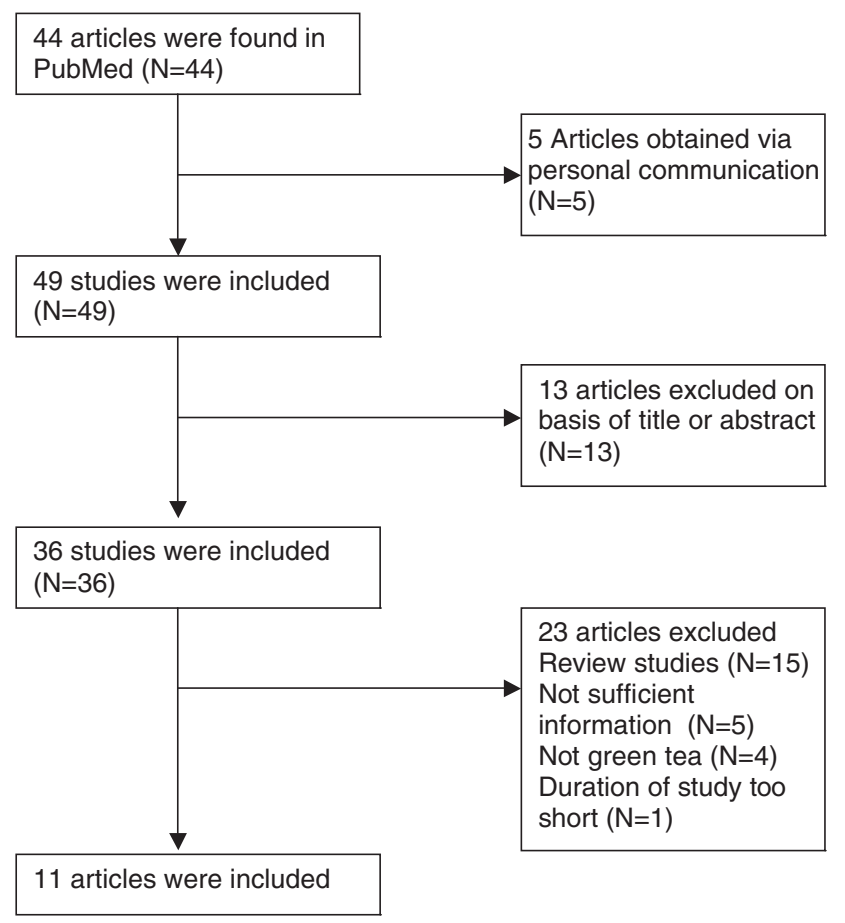

Figure 1 Process of study selection.
From three studies it was possible to calculate more than one effect size estimate. Kozuma et al. ${ }^{10}$ reported their results separately for men and women, which, therefore, yields two effect size estimates for the meta-analysis. Also, the data from Westerterp-Plantenga et al. ${ }^{20}$ allowed the calculation of two estimates, one for subjects with high and the other for subjects with low regular caffeine intake. Finally, three effect size estimates were obtained from the study by Wang et al., ${ }^{17}$ as it contained three treatment groups that received either a different dosage or an equivalent dosage distributed in a different number of servings. A total of 15 effect size estimates could, therefore, be extracted from the 11 studies. Figure 2 shows a plot of the individual effect size estimates with corresponding 95\% confidence intervals.

The random-effects model indicated a modest, but significant positive effect of catechins on WL/WM $(\hat{\mu}=-1.31$, 95\% CI: -2.05 to $-0.57 ; P<0.001)$. Therefore, it is estimated that subjects in the treatment groups lost on average $1.31 \mathrm{~kg}$ more weight (or gained on average $1.31 \mathrm{~kg}$ less weight) than people in the control groups. Removal of any individual study from the meta-analysis did not alter this conclusion (with $\hat{\mu}$ values ranging from -1.07 to -1.47 ; all $P<0.004)$. However, the results were clearly heterogeneous ( $\hat{\mu}=1.13$ with $95 \% \mathrm{CI}: 0.25$ to $3.80 ; I^{2}=94 \%$ with 95\% CI: $77 \%$ to $98.0 \%$; test for heterogeneity: $P<0.001)$.

The difference in dosage of the EGCG-caffeine mixture between the treatment and the placebo group was not a significant moderator, whether examined in combination with the other two moderators or individually $(P=0.34$ and 0.76 , respectively). Although the average effect was larger for studies with Asian $(\hat{\mu}=-1.51,95 \% \mathrm{CI}:-2.37$ to -0.65$)$ than Caucasian ( $\hat{\mu}=-0.82,95 \% \mathrm{CI}:-2.13$ to 0.50 ) samples, the difference did not reach statistical significance $(P=0.19$ when examined in combination with the other two moderators and $P=0.37$ when examined individually).

The estimated effect was larger for samples with a low $(\hat{\mu}=-1.60,95 \% \mathrm{CI}:-2.38$ to -0.83$)$ in comparison to a moderate-to-high regular caffeine intake $(\hat{\mu}=-0.27,95 \% \mathrm{CI}$ : -1.63 to 1.10$)$. The difference was significant when examined in combination with the other moderator, but not when examined individually $(P=0.04$ and $P=0.09$, respectively). The estimated amount of (residual) heterogeneity was equal to $\hat{\tau}^{2}=0.92$ after inclusion of this moderator in the model, suggesting that $\sim 19 \%$ of the total amount of heterogeneity could be accounted for based on information about the regular caffeine intake of the samples in the set of studies.

\section{Discussion}

The results of this meta-analysis show that an EGCGcaffeine mixture has an effect on WL and on WM after a period of negative energy balance. It is also shown that interaction of ethnicity and habitual caffeine intake is a 


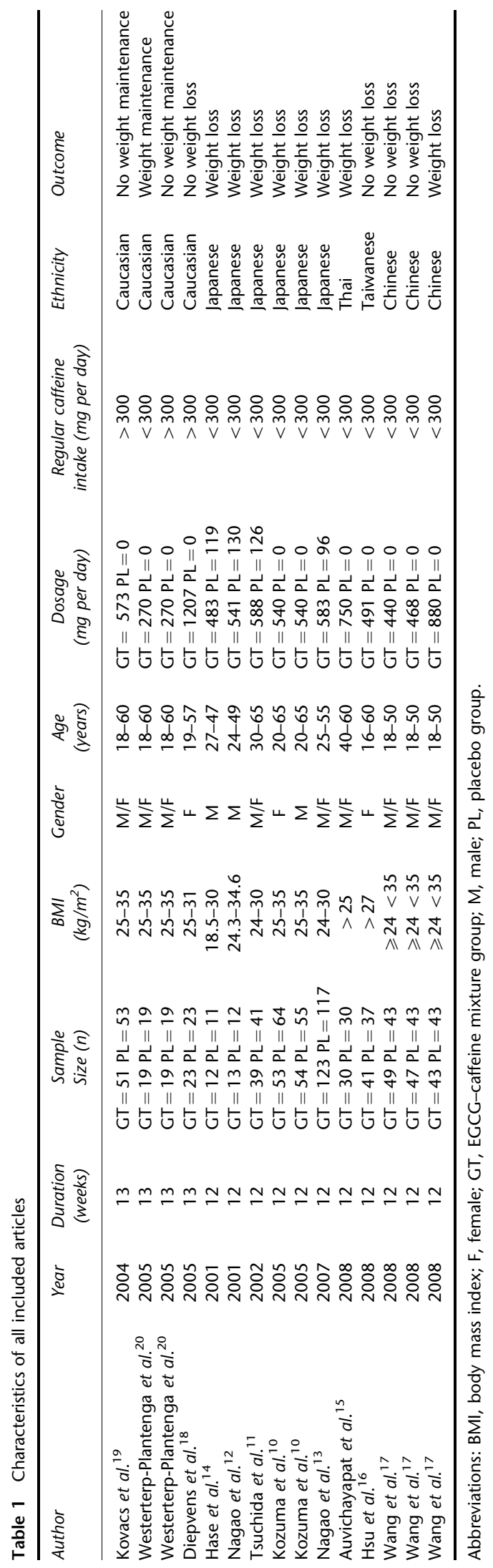

moderator. Dosage of catechins in the treatment or in the placebo did not have any significant effect on the outcome of the studies that were included.

However, the overall result implies some heterogeneity. This may be caused by studies differing in the possible moderators ethnicity and habitual caffeine intake. In particular, all Asian studies had a low caffeine intake and nearly all Caucasian studies had a high caffeine intake. Only one treatment group of the Westerterp-Plantenga et al. ${ }^{20}$ study had a low caffeine intake. Although caffeine intake was a significant moderator when examined together in a model including ethnicity, inclusion of more studies with both ethnicities with different amounts of caffeine intake would provide a clearer picture of how these moderators influence the effectiveness of catechins.

Interaction between the possible moderators maybe due to differences in allele frequencies of polymorphisms between ethnicities. For instance, people who drink caffeine regularly not only get habituated to the effects of caffeine, but also tolerate caffeine intake. Cornelis et al. ${ }^{23}$ showed that Hispanic Americans with an ADORA2A 1083TT genotype are more likely to limit their caffeine intake than the $C C$ and $C T$ genotype. These persons appeared to be more sensitive for the differences between caffeine and the adenosinergic system. This genotype codes for the $\mathrm{A}_{2 \mathrm{a}}$ receptor, at which caffeine antagonizes the actions of adenosine, a key process in the stimulating properties of caffeine. CYP1A2, which codes for the enzymes of cytochrome P450 (the metabolizers of caffeine), does not seem to have a function. ${ }^{23}$ Therefore, it may well be that the habitually low caffeine consumers do not tolerate high amounts of caffeine intake and, therefore, react more sensitively to the small amount of caffeine added to the green tea mixture. When the allele frequencies of the genes coding for the activity of the enzyme differ between ethnic groups, this may explain the observed differences in response to the treatment. For this reason, ethnicity was included as a moderator. Although ethnicity was not a significant moderator, the results suggest that it may affect the effect an EGCG-caffeine mixture has on thermogenesis as the Asian subjects lost more weight than the Caucasian subjects. However, before the moderating role of ethnicity can be examined in more detail, additional studies with Caucasian samples should be conducted to offset the larger number of studies with Asian samples.

The inhibition of several enzymes may be the mechanism by which the components of green tea induce WL/WM. Catechins inhibit the catechol O-methyltransferase (COMT) and caffeine inhibits phosphodiesterase. Levels of norepinephrine and cAMP rise because degradation by these enzymes is ceased. Consequently, parasymphatic activity is increased. ${ }^{8}$ This phenomenon does not appear equally clear in all ethnic groups because of the differences in relevant enzyme activity, causing differences in sensitivity for these ingredients. In that respect, Hodgson et al. ${ }^{24}$ stated that there is a wide variability in flavonoid O-methylation, a major pathway of flavonoid metabolism, by the enzyme COMT. 


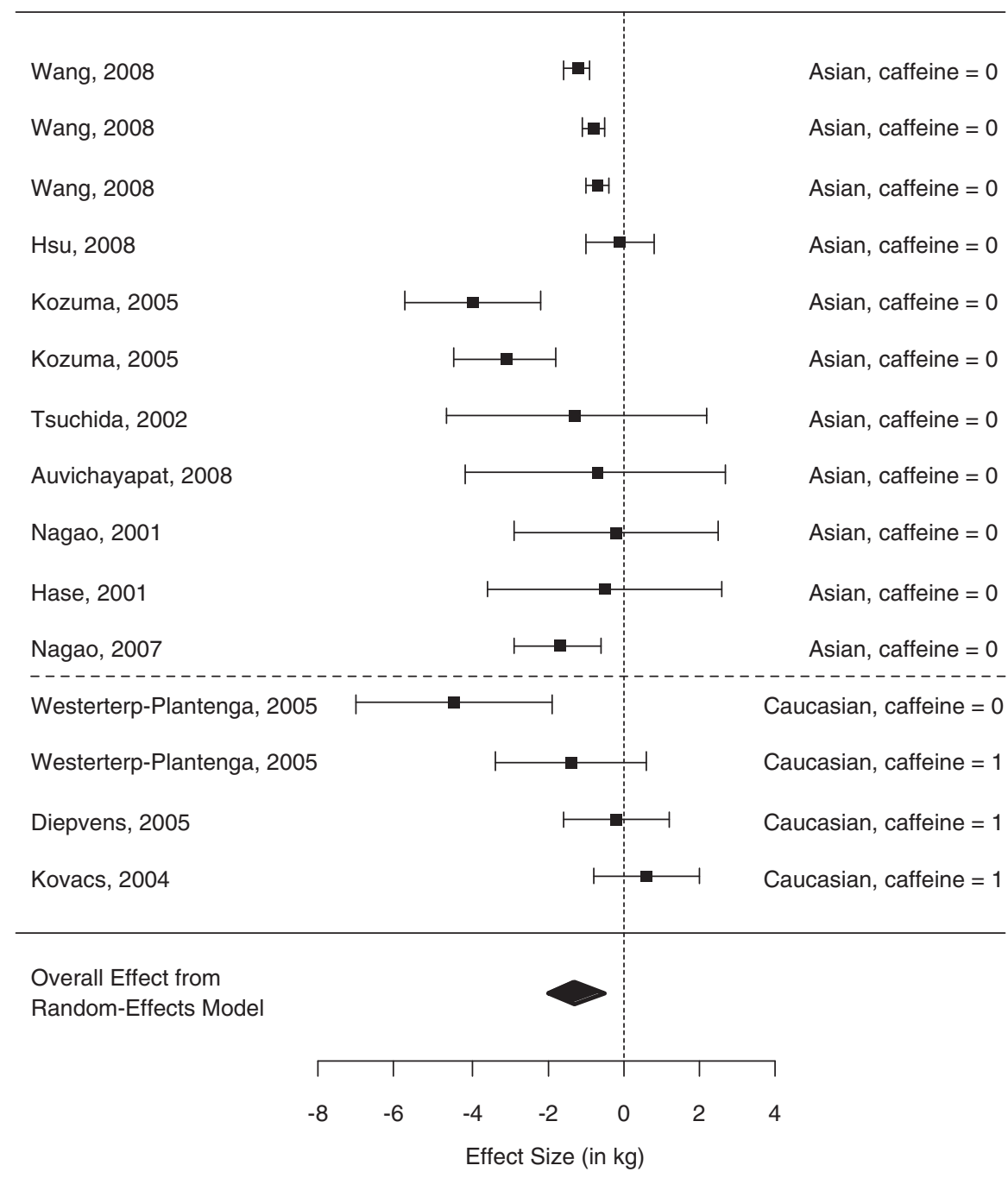

Figure 2 Forest plot of the individual effect size estimates (mean weight change within the treatment group minus mean weight change within the control group) with corresponding $95 \%$ confidence intervals (caffeine $=0 / 1$ for low $(0)$ or moderate-to-high (1) regular caffeine intake).

The inter-individual variability of the activity of COMT could vary as much as three-fold. ${ }^{24}$ Moreover, COMT enzyme activity differs between ethnic groups, ${ }^{25}$ in that Asian populations have a higher frequency of the thermostable, high activity enzyme, COMT ${ }^{\mathrm{H}}$ allele (Val/Val polymorphism) than the Caucasian populations. The Caucasian populations have a higher frequency of the thermolabile, low activity enzyme, COMT ${ }^{\mathrm{L}}$ allele (Met/Met polymorphism). ${ }^{3}$ In all, $50 \%$ of Caucasians are homozygous for the COMT ${ }^{\mathrm{L}}$ allele $(25 \%)$ and $\mathrm{COMT}^{\mathrm{H}}$ allele $(25 \%)$. The other $50 \%$ is heterozygous (Val/Met polymorphism). ${ }^{25}$ This may explain the difference in sensitivity to interventions with EGCG-caffeine mixtures, and why, in some studies with Caucasian subjects, no effect was seen after ingestion of an EGCG-caffeine mixture. The observations described above suggest interaction between the two possible moderators. Not until the two moderators were taken together, the difference in estimated effect between samples with low and moderate-to-high regular caffeine intake became significant, probably because of coincidence of polymorphisms ADORA2A, COMT, and ethnicity.

The results of the meta-analysis also show that the difference in dosage of the catechins in the EGCG-caffeine mixture between treatment and control groups had no effect on the size of the effect. This finding is consistent with the results from the study of Berube-Parent et al. ${ }^{9}$ in which four different mixtures of EGCG and caffeine with a different dosage of catechins were examined. The results from that study showed that all mixtures increased 24-h energy expenditure and that the increase was similar for all doses of EGCG in the mixtures, which was also found in the study from Wang et al. ${ }^{17}$

Taken together, this meta-analysis has shown that EGCGcaffeine mixtures have a positive effect on WL and on WM. 
Moreover, it also shows that habitual caffeine intake and ethnicity may be moderators, especially because of interactions of the different ADORA2A and COMT polymorphisms and ethnicity, whereas different doses of catechins do not have a significantly different effect. Experimental research is needed to find out whether and to what extent people are genetically predisposed for the effect of EGCG-caffeine mixtures.

\section{Conflict of interest}

The authors declare no conflict of interest.

\section{Acknowledgements}

RH and MSW-P designed the study. RH collected and prepared the data. WV analyzed the data. $\mathrm{RH}$ and $\mathrm{WV}$ wrote the manuscript and MSW-P contributed to the interpretation of the data and reviewed the manuscript. The study was executed under the supervision of MSW-P.

\section{References}

1 Shixian Q, VanCrey B, Shi J, Kakuda Y, Jiang Y. Green tea extract thermogenesis-induced weight loss by epigallocatechin gallate inhibition of catechol-O-methyltransferase. J Med Food 2006; 9: 451-458.

2 Wolfram S, Wang Y, Thielecke F. Anti-obesity effects of green tea: from bedside to bench. Mol Nutr Food Res 2006; 50: 176-187.

3 Krul C, Luiten-Schuite A, Tenfelde A, van Ommen B, Verhagen H, Havenaar R. Antimutagenic activity of green tea and black tea extracts studied in a dynamic in vitro gastrointestinal model. Mutat Res 2001; 474: 71-85.

4 Langley-Evans SC. Antioxidant potential of green and black tea determined using the ferric reducing power (FRAP) assay. Int J Food Sci Nutr 2000; 51: 181-188.

5 Serafini M, Ghiselli A, Ferro-Luzzi A. In vivo antioxidant effect of green and black tea in man. Eur J Clin Nutr 1996; 50: 28-32.

6 Westerterp-Plantenga M, Diepvens K, Joosen AM, Berube-Parent $\mathrm{S}$, Tremblay A. Metabolic effects of spices, teas, and caffeine. Physiol Behav 2006; 89: 85-91.

7 Diepvens K, Westerterp KR, Westerterp-Plantenga MS. Obesity and thermogenesis related to the consumption of caffeine, ephedrine, capsaicin, and green tea. Am J Physiol Regul Integr Comp Physiol 2007; 292: R77-R85.

8 Dulloo AG, Duret C, Rohrer D, Girardier L, Mensi N, Fathi M et al. Efficacy of a green tea extract rich in catechin polyphenols and caffeine in increasing 24-h energy expenditure and fat oxidation in humans. Am J Clin Nutr 1999; 70: 1040-1045.

9 Berube-Parent S, Pelletier C, Dore J, Tremblay A. Effects of encapsulated green tea and Guarana extracts containing a mixture of epigallocatechin-3-gallate and caffeine on $24 \mathrm{~h}$ energy expenditure and fat oxidation in men. Br J Nutr 2005; 94: 432-436.

10 Kozuma K, Chikama A, Hishino E, Kataoka K, Mori K, Hase Tet al. Effect of intake of a beverage containing $540 \mathrm{mg}$ catechins on the body composition of obese women and men. Prog Med 2005; 25: 185-197.

11 Tsuchida T, Itakura $\mathrm{H}$, Nakamura $\mathrm{H}$. Reduction of body fat in humans by long-term ingestion of catechins. Prog Med 2002; 22: 2189-2203.

12 Nagao T, Meguro S, Soga S, Otsuka A, Hase T, Tanaka Y et al. Tea catechins suppress accumulation of body fat in humans. J Oleo Sci 2001; 50: 717-728.

13 Nagao T, Hase T, Tokimitsu I. A green tea extract high in catechins reduces body fat and cardiovascular risks in humans. Obesity (Silver Spring) 2007; 15: 1473-1483.

14 Hase T, Komine Y, Meguro S, Takeda Y, Takahashi H, Matsui Y et al. Anti-obesity effects of tea catechins in humans. J Oleo Sci 2001; 50: 599-605.

15 Auvichayapat P, Prapochanung M, Tunkamnerdthai O, Sripanidkulchai BO, Auvichayapat N, Thinkhamrop B et al. Effectiveness of green tea on weight reduction in obese Thais: a randomized, controlled trial. Physiol Behav 2008; 93: 486-491.

$16 \mathrm{Hsu}$ CH, Tsai TH, Kao YH, Hwang KC, Tseng TY, Chou P. Effect of green tea extract on obese women: a randomized, double-blind, placebo-controlled clinical trial. Clin Nutr 2008; 27: 363-370.

17 Wang M, Wen Y, Du Y, Yan X, Wei Guo H, Rycroft J et al. The effects of 90 days consumption of a high-catechin green tea beverage on body weight. Eur J Clin Nutr 2009. (Submitted).

18 Diepvens K, Kovacs EM, Nijs IM, Vogels N, Westerterp-Plantenga MS. Effect of green tea on resting energy expenditure and substrate oxidation during weight loss in overweight females. Br J Nutr 2005; 94: 1026-1034.

19 Kovacs EM, Lejeune MP, Nijs I, Westerterp-Plantenga MS. Effects of green tea on weight maintenance after body-weight loss. $\mathrm{Br} \mathrm{J}$ Nutr 2004; 91: 431-437.

20 Westerterp-Plantenga MS, Lejeune MP, Kovacs EM. Body weight loss and weight maintenance in relation to habitual caffeine intake and green tea supplementation. Obes Res 2005; 13: 1195-1204.

21 Viechtbauer W. Bias and efficiency of meta-analytic variance estimators in the random-effects model. J Educ Behav Stat 2005; 30: 261-293.

22 Grigg D. The worlds of tea and coffee: patterns of consumption. GeoJournal 2002; 57: 283-294.

23 Cornelis MC, El-Sohemy A, Campos H. Genetic polymorphism of the adenosine $\mathrm{A} 2 \mathrm{~A}$ receptor is associated with habitual caffeine consumption. Am J Clin Nutr 2007; 86: 240-244.

24 Hodgson JM, Puddey IB, Burke V, Croft KD. Is reversal of endothelial dysfunction by tea related to flavonoid metabolism? Br J Nutr 2006; 95: 14-17.

25 Palmatier MA, Kang AM, Kidd KK. Global variation in the frequencies of functionally different catechol-O-methyltransferase alleles. Biol Psychiatry 1999; 46: 557-567. 